\title{
In situ FTIRRAS study of the electro-oxidation reactions of thiourea and gold in aqueous acid solutions
}

\author{
A.E. Bolzán ${ }^{\mathrm{a}, *}$, T. Iwasita $^{\mathrm{b}}$, A.J. Arvia ${ }^{\mathrm{a}}$ \\ a Instituto de Investigaciones Fisicoquímicas Teóricas y Aplicadas (INIFTA) (UNLP, CONICET), Sucursal 4, Casilla de Correo 16, (1900) La Plata, \\ Argentina \\ ${ }^{\mathrm{b}}$ Instituto de Quimica de São Carlos, Universidade de São Paulo, Sao Carlos, Brazil
}

Received 21 October 2002; received in revised form 15 December 2002; accepted 4 January 2003

\begin{abstract}
The electro-oxidation of gold and thiourea (TU) in aqueous acid solutions is investigated by means of in situ FTIRRAS measurements complemented by voltammetry. The formation of soluble species related to the gold(I)-TU complex and TU electrooxidation products is monitored by following the changes in the IR spectra with the applied potential in the range $-0.1-1.5 \mathrm{~V}$. Experimental data show that gold electrodissolution produces soluble $\left[\mathrm{Au}\left(\mathrm{CS}\left(\mathrm{NH}_{2}\right)_{2}\right)_{2}\right]_{2} \mathrm{SO}_{4}$ species. The IR spectrum of solid samples of this complex is reported. The electrodissolution reaction begins at approximately $0.15 \mathrm{~V}$ (SHE), concomitantly with the early stages of TU electro-oxidation. The electro-oxidation of TU on gold in acid solutions produces formamidine disulphide (FDS) at potentials below 1.2 V (SHE). The formation of the gold complex and that of FDS are quasi-reversible processes, as revealed by FTIRRAS data. Once the formation of the oxygen-containing layer on gold sets in, the electro-oxidation of TU and FDS yields carbon dioxide, sulphate ions and CN-containing products. Adsorbed sulphate species, which are also detected from $1.2 \mathrm{~V}$ upwards, exhibit a band shift of $27 \mathrm{~cm}^{-1} \mathrm{~V}^{-1}$.
\end{abstract}

(C) 2003 Elsevier Science B.V. All rights reserved.

Keywords: Thiourea; Electro-oxidation; Formamidine disulphide; FTIRRAS; Gold; Electrodissolution

\section{Introduction}

Thiourea (TU) is a relatively small molecule that is used for different purposes of technological interest. At low concentration, it acts as an inhibitor to prevent the corrosion of active metals such as iron [1] and copper $[2,3]$, as a catalyst for the electroreduction of metal ions such as $\mathrm{Zn}(\mathrm{II})$ and $\mathrm{Cd}(\mathrm{II})[4,5]$ or as an additive for electrolytically driven lattice formation processes such as in copper deposition [6]. On the other hand, at high concentration, TU appears as a promising extracting agent of precious metals from their ores [7-9], because of its complex forming capability. In the case of gold, it results in the formation of complex salts containing the $\left[\mathrm{Au}(\mathrm{TU})_{2}\right]^{+}$cation. The syntheses of this complex cation as bromide [10], chloride [11] and sulphate [11]

* Corresponding author. Fax: +54-221-4254642.

E-mail address: aebolzan@inifta.unlp.edu.ar (A.E. Bolzán). salts and their structures, determined by X-ray diffraction, have been reported.

The specific adsorption and electroadsorption of TU on different metal surfaces, including gold, are very strong, as is concluded from surface enhanced Raman spectroscopy [12-14] and electrochemical techniques [14-16]. There is general agreement that in these processes the main gold-TU interactions occurs via the sulphur atom $[14,17]$. Radiotracer data have been used to determine the range of potentials related to the stability of TU adsorbates on gold [18]. At potentials more negative than those where TU electroadsorption takes place, there is evidence of sulphiding of the gold electrode, whereas at the positive potential side, adsorbate electro-oxidation produces a number of byproducts [18].

The anodic oxidation of $\mathrm{TU}$ in aqueous acid solutions either on platinum [19], copper [20] or gold [16], exhibits a first quasi-reversible stage related to the formation of formamidine disulphide (FDS) as the main product. 
FDS is also produced relatively easily by homogeneous reactions in solution between TU and oxidants such as hydrogen peroxide [21]. In any case, FDS can be further oxidised to either elemental sulphur or sulphate ions [22,23] and cyanamide [23]. The formation of carbon dioxide from TU electro-oxidation has also been proposed [16]. In fact, it is known that FDS in aqueous acids is unstable and decomposes irreversibly into cyanamide and elemental sulphur [22].

The electrodissolution of gold in aqueous TU-containing acid solutions proceeds with $100 \%$ efficiency for $E<0.3 \mathrm{~V}$ (SHE), while for $E>0.3 \mathrm{~V}$ the reaction is accompanied by TU electro-oxidation to FDS and other byproducts [24]. Correspondingly, the efficiency of gold electrodissolution decreases. TU electro-oxidation to FDS either precedes or at least occurs concomitantly with the electrodissolution of gold, depending on the concentration of TU [16]. The latter occurs even in the potential range related to the formation of the oxygencontaining layer on gold. In the potential range of this process, strongly bound adsorbates produced from TU are also electro-oxidised, seemingly yielding sulphate and carbon dioxide as the main products [16]. This agrees, to some extent, with the presence of sulphur octomers at potentials beyond the formation of FDS adsorbates on $\mathrm{Au}$ (1 111 ), which has been detected by STM imaging [25].

In spite of increasing interest in the gold $\mid$ TU aqueous interface, no in situ identification of the reaction products has been attempted. In fact, in situ spectroscopic techniques have mostly been applied to study TU adsorption on gold and the resulting adsorbate structures [14,25]. FTIRRAS can be considered as a suitable tool to identify and follow the in situ evolution of reactants and products involved in the complex reaction system encountered at the gold $\mid$ aqueous TU electrochemical interface [23,26-28]. In fact, this technique has been used to monitor the adsorption of TU on copper [29], iron [26] and silver [28] and its electro-oxidation on platinum [23].

In the present work the simultaneous electro-oxidation of polycrystalline gold and TU in aqueous acid solutions was investigated with the aim of identifying reactants and products, and changes of their concentration at the metal $\mid$ solution interface. Attention was also paid to the formation of gold-TU complex species.

\section{Experimental}

In situ FTIRRAS experiments were performed using a Nicolet Nexus 670 spectrometer equipped with a liquid nitrogen cooled MCT detector. The spectroelectrochemical cell was fitted with a $60^{\circ}$ prismatic calcium fluoride window. The working electrode was a mirror-polished gold disk $0.7-\mathrm{cm}$ in diameter. Before each run it was mechanically polished with alumina $0.3-\mu \mathrm{m}$ grit and rinsed with acetone and Milli-Q water. A reversible hydrogen electrode was used as the reference electrode and a gold foil surrounding the working electrode was employed as the counter electrode.

Normalised reflectance spectra were calculated as $R /$ $R_{0}$, where $R$ is the value of the reflectance at the sampling potential $E_{\mathrm{s}}$ and $R_{0}$ is the reflectance measured at a reference potential $E_{\text {ref. }}$. The value of $E_{\text {ref }}$ was set slightly below the rest potential of gold in the working solution, i.e., a value where TU electro-oxidation is precluded, in order to follow the formation of electrooxidation products. Occasionally, the electrode was immersed at a sufficiently negative $\left(E_{\text {ref }}=-0.1 \mathrm{~V}\right)$ or positive $\left(E_{\text {ref }}=0.3 \mathrm{~V}\right)$ potential, that allowed us to establish well-defined reduction and oxidation reference states and follow the appearance and disappearance of soluble products during the initial stages of TU and gold electro-oxidation. Accordingly, positive- and negativegoing absorption bands in the spectra represent the loss and gain of species at $E_{\mathrm{s}}$ as compared to $E_{\mathrm{ref}}$, respectively. At each sampling potential, either 256 or 512 interferograms with $8 \mathrm{~cm}^{-1}$ resolution were computed. Parallel (p) and perpendicular (s) polarised light was obtained from a barium fluoride supported aluminiumwire grid polariser. For the FTIRRAS experiments, the electrode potential was controlled by means of a Wenking potentiostat and a potential step generator.

Attenuated total reflection (ATR) spectra were obtained for TU and FDS in aqueous $0.1 \mathrm{M}$ perchloric acid using a germanium prism. The background spectra were recorded by adding $0.1 \mathrm{ml}$ of aqueous $0.1-\mathrm{M}$ perchloric acid. Subsequently, $0.1 \mathrm{ml}$ of either aqueous $0.1 \mathrm{M}$ TU or $0.1 \mathrm{M}$ FDS $+0.1 \mathrm{M}$ perchloric acid was added to record the ATR spectra of TU and FDS, respectively.

The IR spectrum disk-shaped solid sample corresponding to $\left[\mathrm{Au}(\mathrm{TU})_{2}\right]_{2} \mathrm{SO}_{4}$ and potassium bromide was determined in the region $4000-400 \mathrm{~cm}^{-1}$ by means of a Shimadzu spectrometer. For this purpose, the complex salt was prepared as indicated elsewhere [11].

Complementary voltammetric runs were performed utilising a conventional three electrode cell with a polycrystalline gold wire working electrode $\left(0.25 \mathrm{~cm}^{2}\right.$ geometric area, J. Matthey, spec pure), a large platinum sheet $\left(2 \mathrm{~cm}^{2}\right.$ apparent area) as the counter electrode, and a mercurous sulphate electrode, as the reference. The working electrode was polished mechanically with alumina and rinsed with Milli-Q water before each experiment. For these measurements, the electrochemical setup consisted of an LYP potentiostat coupled to a waveform generator.

Working solutions were prepared from TU (Fluka, puriss.), FDS dihydrochloride (FDS $\cdot 2 \mathrm{HCl}, \mathrm{ICN}, 97 \%$ ), sulphuric acid (97\% Merck, p.a.), perchloric acid (70\% Merck, p.a.) and either Milli-Q water or deuterium 
oxide (Aldrich, 99.9\%). The latter was employed to study the FTIRRAS spectra in the region where water bands obscure the presence of those related to TU and FDS. All solutions were saturated with nitrogen before the experiments.

All the experiments were performed at room temperature.

\section{Results and interpretation}

\subsection{Voltammetry}

The voltammogram of gold in aqueous $0.1 \mathrm{M} \mathrm{TU}+$ $0.5 \mathrm{M}$ sulphuric acid at $0.05 \mathrm{~V} \mathrm{~s}^{-1}$ (Fig. 1a) shows a small anodic peak (Ia) at approximately $0.46 \mathrm{~V}$ and a large anodic peak (IIa) at $0.9 \mathrm{~V}$. Peak IIa is followed by an anodic current with a hump (peak IIIa) at approximately $1.2 \mathrm{~V}$ (peak IIa/IIIa height ratio $>1$ ). Then, the anodic current decreases slowly as $E$ approaches $1.6 \mathrm{~V}$. The subsequent reverse scan shows a quasi linear decrease in the anodic current from 1.6 to $1.3 \mathrm{~V}$, peaks IIIa and IIa which are overlapped to a great extent, and exhibit a current ratio (IIa/IIIa) $<1$. From 0.6 to $0.2 \mathrm{~V}$, the anodic current becomes almost constant, and finally cathodic peak Ic at $0.12 \mathrm{~V}$ and hump IIc at approximately $0 \mathrm{~V}$ are recorded.
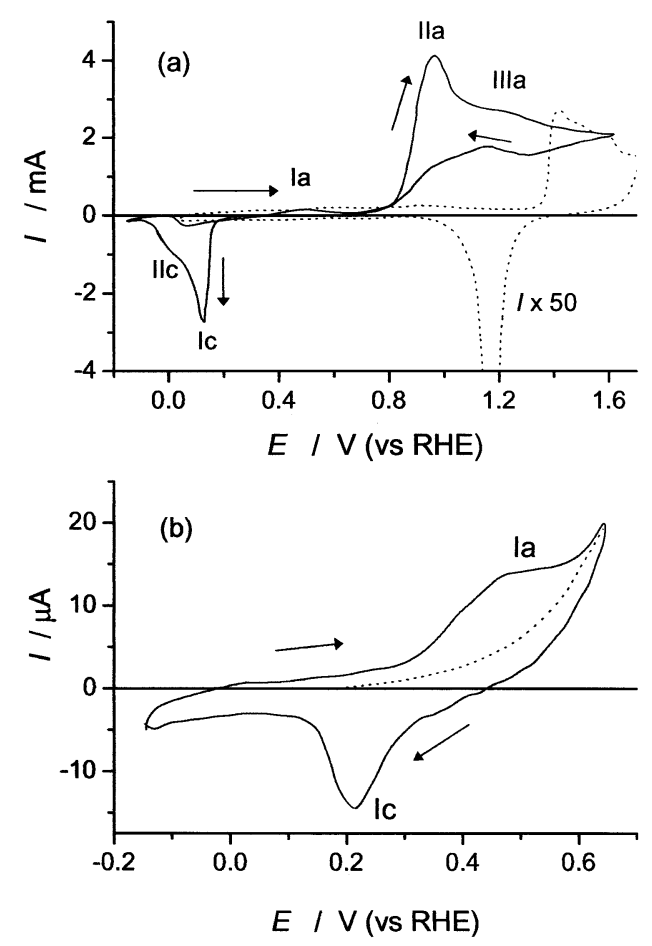

Fig. 1. (a) Voltammograms of gold in $0.5 \mathrm{M}$ sulphuric acid (dashed line) and $0.1 \mathrm{M} \mathrm{TU}+0.5 \mathrm{M}$ sulphuric acid (full line) run between -0.2 and $1.65 \mathrm{~V}$. (b) Voltammogram of gold in $0.1 \mathrm{M} \mathrm{TU}+0.5 \mathrm{M}$ sulphuric acid run between -0.2 and $0.65 \mathrm{~V}$; the dashed line shows the extrapolation of peak IIa to $I=0 . v=0.05 \mathrm{~V} \mathrm{~s}^{-1}$.
In the range between -0.15 and $0.65 \mathrm{~V}$, the voltammogram (Fig. 1b) shows conjugated peaks Ia at approximately 0.45 and Ic at approximately $0.22 \mathrm{~V}$. This pair of peaks is related to the TU/FDS redox couple [16,19,30]. After peak Ia, the anodic current starts to increase due to the electrodissolution of gold. This process is responsible for the appearance of peak IIa (Fig. 1a), but the formation of soluble gold complexes presumably started at lower potentials concomitantly with the formation of FDS from TU. This assertion is supported by data from the extrapolation to $I \rightarrow 0$ of the faradaic current related to peak IIa (Fig. $1 \mathrm{~b}$ ), and it agrees with the prediction of the potential$\mathrm{pH}$ aqueous solution diagrams for the gold-TU-water system [31], indicating that for $0.1 \mathrm{M} \mathrm{TU}+10^{-6} \mathrm{M}$ gold ion in $0.5 \mathrm{M}$ sulphuric acid, the formation of soluble gold complex species should occur at approximately $0.22 \mathrm{~V}$ [31]. It should be noted that the stability domain for gold complexes depends on both the gold ion and TU concentration $\left(c_{\mathrm{TU}}\right)$. Thus, it becomes smaller either on increasing gold ion concentration at constant $c_{\mathrm{TU}}$ or increasing $c_{\mathrm{TU}}$ at constant gold ion concentration [31].

To confirm that peaks Ia and IIa are related to the electro-oxidation of TU to FDS and to gold electrodissolution, respectively, voltammograms restricted to the potential range of either peak Ia or peak IIa were obtained (Fig. 2). For peak Ia, on reversing the potential scan at approximately $0.45 \mathrm{~V}$ (Fig. 2a) the decrease in current that should be expected for a pseudocapacitive process is observed prior to peak Ic. But, when the voltammetric run is extended to the potential range of

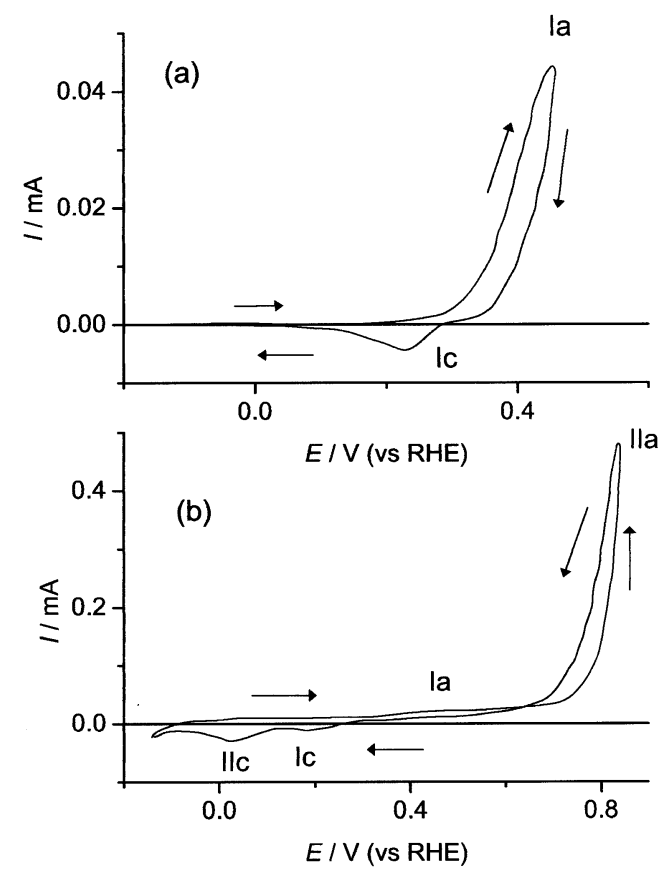

Fig. 2. Voltammograms of gold in $0.1 \mathrm{M} \mathrm{TU}+0.5 \mathrm{M}$ sulphuric acid run between -0.2 and $0.45 \mathrm{~V}$. (a) and -0.2 and $0.83 \mathrm{~V}$ (b) $v=0.05$ $\mathrm{V} \mathrm{s}^{-1}$. 
peak IIa (Fig. 2b), the reverse scan shows an anodic current loop that resembles those usually observed for metal electrodissolution in aggressive environments. Nevertheless, voltammetric data are consistent with the main processes associated with peaks Ia and IIa referred to above, although this does not preclude the possibility that the chemical dissolution of gold by TU at lower potentials may be suppressed. As is shown further on, the formation of gold soluble complexes is feasible even in the potential range of peak Ia.

On the other hand, a voltammogram run at 0.005 $\mathrm{V} \mathrm{s}^{-1}$ (Fig. 3) shows successive anodic peaks, namely, peak Ia at approximately 0.44 , peak IIa at approximately $0.92 \mathrm{~V}$, hump IIIa at approximately $1.2 \mathrm{~V}$, and peak IVa at approximately $1.40 \mathrm{~V}$. During the reverse potential scan, the anodic current decreases to a minimum at $1.37 \mathrm{~V}$, then it rises to hump IIIa and decreases again rather rapidly showing a hump close to the potential of peak IIa, and eventually attains a rather constant current from approximately 0.6 to $0.3 \mathrm{~V}$. The voltammograms run at the lowest potential scan rate show no cathodic current peak. Therefore, peak Ic and hump IIc, which are observed at higher scan rates, should be related to the electroreduction of soluble species produced from both TU and gold electrooxidation reactions. These products diffuse away from the reaction interface and are not detected at $v$

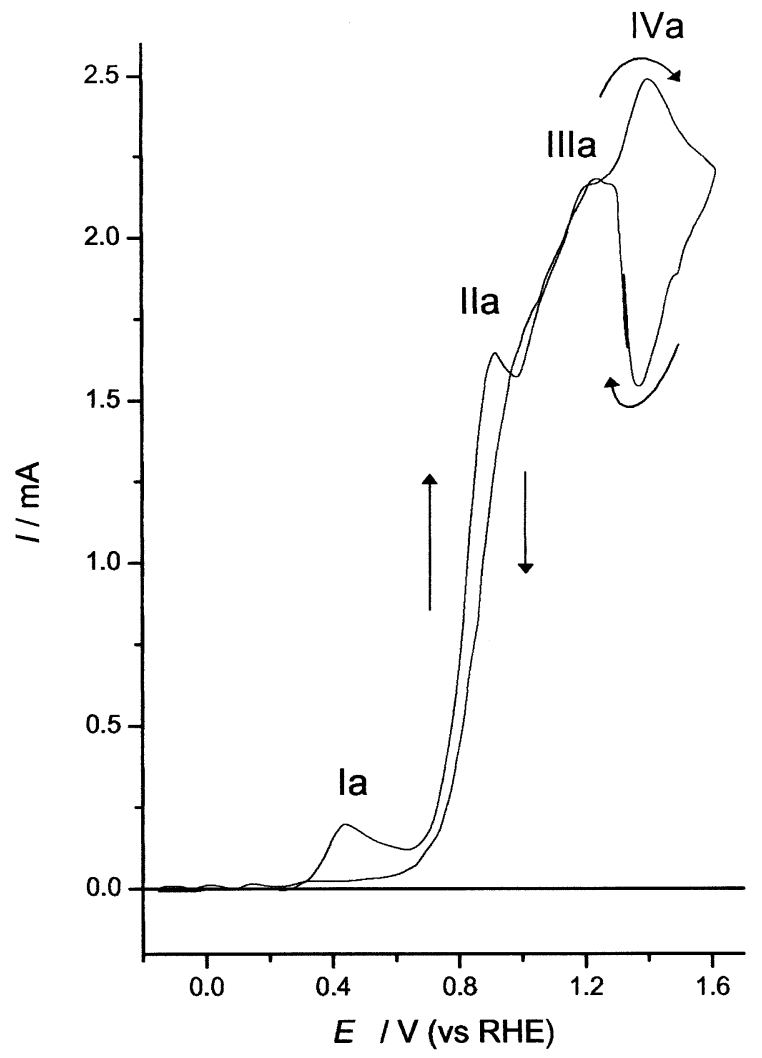

Fig. 3. Voltammograms of gold in aqueous $0.1 \mathrm{M} \mathrm{TU}+0.5 \mathrm{M}$ sulphuric acid run between -0.2 and $1.65 \mathrm{~V} . v=0.005 \mathrm{~V} \mathrm{~s}^{-1}$. sufficiently low. In fact, similar experiments with decreasing $v$ show a gradual decrease in the cathodic current contribution in the $0.4-0.0 \mathrm{~V}$ range, as $v$ is decreased.

\subsection{ATR spectra of TU and FDS in $0.1 M$ aqueous perchloric acid}

ATR spectra of TU and FDS in aqueous $0.1 \mathrm{M}$ perchloric acid as well as that of aqueous $0.1 \mathrm{M}$ perchloric acid (blank) were measured in the range $1000-2000 \mathrm{~cm}^{-1}$. The spectrum of TU (Fig. 4a) shows a band at $1100 \mathrm{~cm}^{-1}$ related to the asymmetric stretching of perchlorate ion, and two bands at $1405 \mathrm{~cm}^{-1}$, due to $\mathrm{CN}$ and $\mathrm{CS}$ stretchings and $\mathrm{NH}_{2}$ rocking modes [23], and $1627 \mathrm{~cm}^{-1}$ due to the bending of the $\mathrm{NH}_{2}$ group of TU [23].
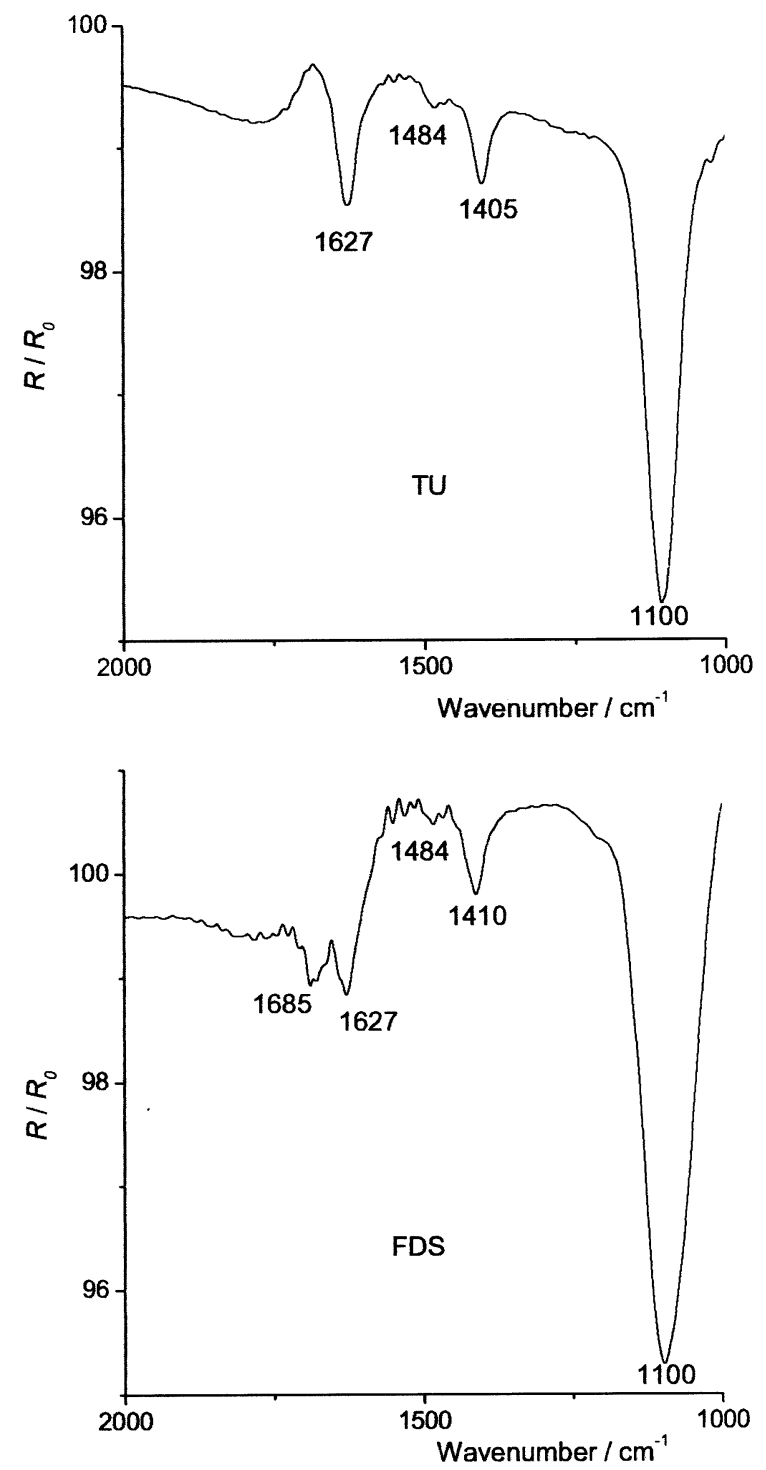

Fig. 4. ATR spectra obtained for (a) $0.1 \mathrm{M} \mathrm{TU}+0.1 \mathrm{M}$ perchloric acid and (b) $0.1 \mathrm{M}$ FDS $+0.1 \mathrm{M}$ perchloric acid. 
The spectrum of FDS (Fig. 4b) shows bands at 1100, 1410,1627 and $1685 \mathrm{~cm}^{-1}$. The FDS bands are slightly blue-shifted as compared to that of TU. For FDS in Nujol [32], absorption bands at 1400, 1630 and 1654 $\mathrm{cm}^{-1}$ have been reported. They were assigned to the stretching of the $\mathrm{CN}_{2}$ and $\mathrm{C}-\mathrm{S}$ bonds and rocking of the $\mathrm{NH}_{2}$ group $\left(1400 \mathrm{~cm}^{-1}\right)$, bending of $\mathrm{NH}_{2}$ and stretching of $\mathrm{CN}_{2}$ groups $\left(1630 \mathrm{~cm}^{-1}\right)$, and bending of the $\mathrm{NH}_{2}$ group $\left(1654 \mathrm{~cm}^{-1}\right)$.

\subsection{IR spectrum of solid $\left[\mathrm{Au}(\mathrm{TU})_{2}\right]_{2} \mathrm{SO}_{4}$ in $\mathrm{KBr}$}

It has recently been found that the dissolution of gold in TU-containing acid solutions produces a soluble gold(I)-TU complex ion (hereafter simply denoted as a gold complex) of formula $\left(\mathrm{Au}[\mathrm{TU}]_{2}\right)^{+}[16]$. The IR spectrum of the sulphate salt of this complex ion is reported here for the first time. This spectrum will be used as a guide for identification of soluble goldcontaining products during anodisation at different potentials in TU-containing acid solutions.

For this purpose, the IR spectrum of $\left(\mathrm{Au}[\mathrm{TU}]_{2}\right)_{2} \mathrm{SO}_{4}$ was measured using a potassium bromide disk. The resulting spectrum for the spectral region 400-2000 $\mathrm{cm}^{-1}$ is depicted in Fig. 5. By comparing the absorption bands exhibited by the gold complex with those reported for TU (Table 1), the following tentative assignments can be advanced. The medium band at $709 \mathrm{~cm}^{-1}$ is

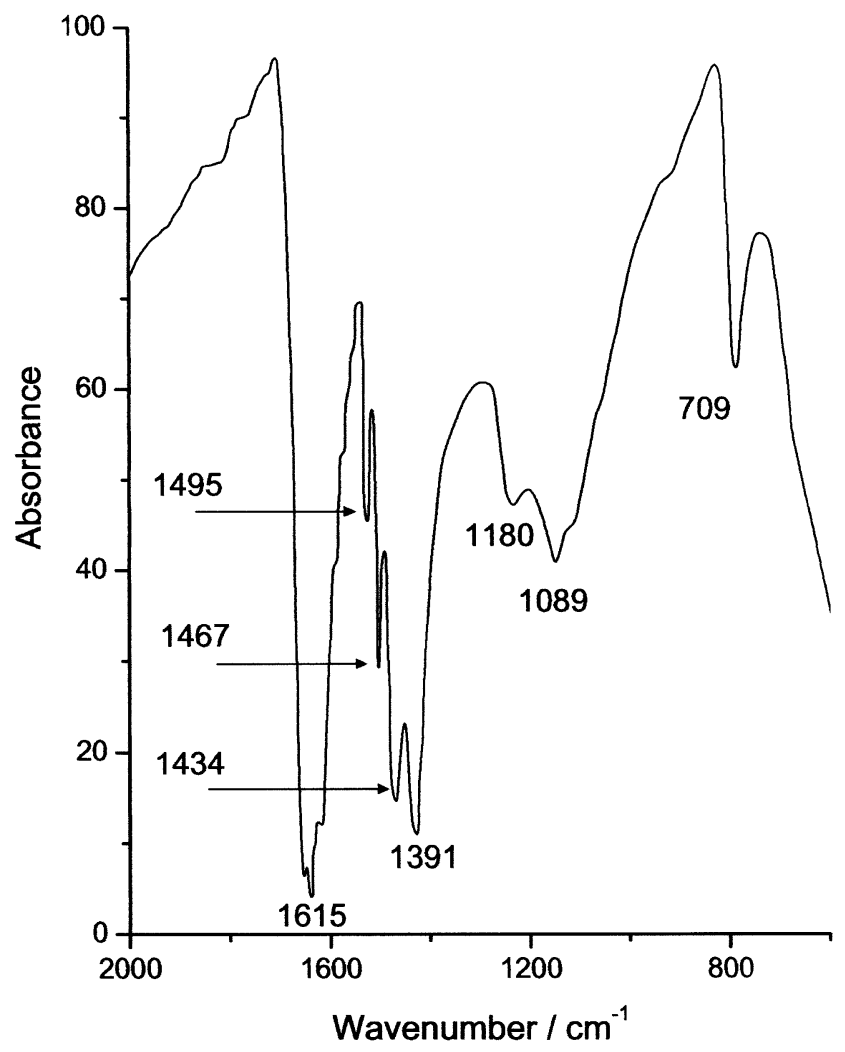

Fig. 5. IR spectrum of solid $\left(\mathrm{Au}[\mathrm{TU}]_{2}\right)_{2} \mathrm{SO}_{4}$ in a $\mathrm{KBr}$ disk.
Table 1

Principal infrared bands of TU

\begin{tabular}{|c|c|c|}
\hline Frequency $/ \mathrm{cm}^{-1}$ & Assignment & References \\
\hline 1040 & $\rho \mathrm{NH}_{2}+v_{\mathrm{as}} \mathrm{CN}_{2}$ & [32] \\
\hline $1083 \mathrm{~s}$ & $\rho \mathrm{NH}_{2}+v_{\mathrm{s}} \mathrm{CN}_{2}$ & [32] \\
\hline 1083 & $v \mathrm{NCN}+\rho \mathrm{NH}_{2}+v \mathrm{CS}$ & [53] \\
\hline 1084 & $v \mathrm{CN}+\rho \mathrm{NH}_{2}$ & [46] \\
\hline $1086 \mathrm{~m}$ & $v_{5}(\rho \mathrm{NH})_{\mathrm{a} 1}+v_{17}(\rho \mathrm{NH})_{\mathrm{b} 2}$ & [54] \\
\hline 1088 & $\rho \mathrm{NH}_{2}+v_{5} \mathrm{CN}_{2}$ & [47] \\
\hline $1407 \mathrm{~s}$ & $v \mathrm{CS}+v \mathrm{CN}$ & [55] \\
\hline $1413 v s$ & $v \mathrm{CN}_{2}+\rho \mathrm{NH}_{2}+v \mathrm{CS}$ & [32] \\
\hline $1413 \mathrm{~s}$ & $v_{4}(v \mathrm{CS})_{\mathrm{a} 1}$ & [54] \\
\hline 1414 & $v \mathrm{CN}+\delta \mathrm{NH}_{2}+\Delta \mathrm{NCN}+v \mathrm{CS}$ & [46] \\
\hline 1415 & $v_{5} \mathrm{CN}_{2}+v \mathrm{CS}+\rho \mathrm{NH}_{2}+\delta \mathrm{NH}_{2}+\delta \mathrm{CN}_{2}$ & [47] \\
\hline 1417 & $\delta \mathrm{NH}_{2}+v \mathrm{NCN}+v \mathrm{CS}$ & [53] \\
\hline 1470 & $v \mathrm{NCN}$ & [53] \\
\hline $1470 \mathrm{~s}$ & $v \mathrm{CS}+v \mathrm{CN}$ & [55] \\
\hline $1472 v s$ & $v_{\mathrm{as}} \mathrm{CN}_{2}+\delta \mathrm{NH}_{2}$ & [32] \\
\hline $1473 \mathrm{~s}$ & $v_{16}(v \mathrm{CN})_{\mathrm{b} 2}$ & [54] \\
\hline 1473 & $v \mathrm{CN}$ & [46] \\
\hline $1588 v s$ & $\delta \mathrm{NH}_{2}+v_{\mathrm{as}} \mathrm{CN}_{2}$ & [32] \\
\hline 1610 & $\delta \mathrm{NH}_{2}$ & [53] \\
\hline $1612 \mathrm{vs}$ & $v_{3}(\delta \mathrm{NH}) \mathrm{a}_{1}+v_{15}(\delta \mathrm{NH})_{\mathrm{b} 2}$ & [54] \\
\hline 1615 & $\delta \mathrm{NH}_{2}$ & [46] \\
\hline $1615 \mathrm{~s}$ & $\delta \mathrm{NH}$ & {$[55]$} \\
\hline $1617 \mathrm{~s}$ & $\delta \mathrm{NH}_{2}$ & [32] \\
\hline 1628 & $\delta \mathrm{NH}_{2}$ & [47] \\
\hline 3275 & $v \mathrm{NH}_{2}$ & [32] \\
\hline 3380 & $v_{\mathrm{as}} \mathrm{NH}_{2}$ & [32] \\
\hline
\end{tabular}

likely to be due to the $\mathrm{C}-\mathrm{S}$ stretching that for pure $\mathrm{TU}$ appears at $753-758 \mathrm{~cm}^{-1}$ (Tables 1 and 2). The red shift of this band is similar to that found for copper(I)-TU complexes [33] (Table 2). The weak band at 1052 and the strong band at $1089 \mathrm{~cm}^{-1}$ can be associated with rocking modes of $\mathrm{NH}_{2}$ groups and stretching modes of the $\mathrm{CN}_{2}$ group [32], while those strong bands appearing in the range $1391-1495 \mathrm{~cm}^{-1}$ should be mainly due to the stretching of $\mathrm{C}-\mathrm{S}$ and $\mathrm{C}-\mathrm{N}$ bonds. The strong band at $1434 \mathrm{~cm}^{-1}$ is most interesting as it agrees with that found during the electro-oxidation of gold in TUcontaining acid solutions, as described in the next section. Finally, the three strong overlapping bands at 1591,1615 and $1629 \mathrm{~cm}^{-1}$ can be assigned to bending modes of the $\mathrm{NH}_{2}$ groups. The band appearing at 1180 $\mathrm{cm}^{-1}$ is likely to be related to sulphate in the complex salt.

\subsection{FTIRRAS of gold in aqueous $0.1 \mathrm{MTU}+0.5 \mathrm{M}$ sulphuric acid}

FTIRRAS spectra of gold in aqueous $0.1 \mathrm{M} \mathrm{TU}+0.5$ M sulphuric acid were obtained taking $E_{\text {ref }}=0.24 \mathrm{~V}$ and collecting spectra by $0.05 \mathrm{~V}$ decreasing the potential stepwise from $E_{\text {ref }}$ to $-0.1 \mathrm{~V}$ and in reverse from -0.1 $\mathrm{V}$ to $1.5 \mathrm{~V}$, using either p- or s-polarised light. It should be noted that $0.24 \mathrm{~V}$ is a potential slightly lower than 
Table 2

Comparison of IR absorption bands $\left(\mathrm{cm}^{-1}\right.$ ) of solid sample of TU [53,56], copper-TU [33], silver-TU [57] and gold-TU (this paper) complex salts

\begin{tabular}{lllllll}
\hline $\mathrm{TU}$ & $\mathrm{Ag}(\mathrm{TU})$ & $\mathrm{Cu}_{2}(\mathrm{TU})_{5}$ & $\mathrm{Au}(\mathrm{TU})_{2}$ & $\mathrm{Cu}_{2}(\mathrm{TU})_{6}$ & $\mathrm{Cu}_{4}(\mathrm{TU})_{7}$ & Assignment \\
\hline $728 \mathrm{~s}$ & $718 \mathrm{~m}$ & 735 & $712 \mathrm{~m}$ & $700 \mathrm{~m}$ & $709 \mathrm{~m}$ & $v \mathrm{CS}$ \\
$1082 \mathrm{~m}$ & $1103 \mathrm{~s}$ & 1105 & $1105 \mathrm{~s}$ & $1075,1104 \mathrm{~s}$ & 1052 & $v \mathrm{CN}, \rho \mathrm{NH}_{2}$ \\
& $1182 \mathrm{w}$ & & $1194 \mathrm{~m}$ & & $1089 \mathrm{~m}$ & \\
$1410 \mathrm{~s}$ & $1389,1424 \mathrm{~s}$ & 1448 & $1391,1424 \mathrm{~s}$ & $1420 \mathrm{~s}$ & $1391,1434 \mathrm{~s}$ & $v(\mathrm{CN}), v \mathrm{CS}, \rho \mathrm{NH}_{2}$ \\
$1472 \mathrm{~s}$ & $1481 \mathrm{~m}$ & & $1478 \mathrm{~m}$ & $1524 \mathrm{w}$ & $1467,1495 \mathrm{~m}$ & $\nu \mathrm{CN}$ \\
$1615 \mathrm{~s}$ & $1603,1634 \mathrm{~s}$ & 1612,1698 & $1607,1634 \mathrm{~s}$ & $1629 \mathrm{~s}$ & $1615,1629 \mathrm{~s}$ & $\delta \mathrm{NH}_{2}, \delta \mathrm{OH}_{2}$ \\
\hline
\end{tabular}

$E_{\text {rest }}=0.26 \mathrm{~V}$, the rest potential of gold in the working solution.

When $E$ is decreased stepwise from $E_{\text {ref }}$ to $-0.1 \mathrm{~V}$ (Fig. 6), p-polarised light spectra exhibit only broad negative bands at 1200 and $1650 \mathrm{~cm}^{-1}$ related to bisulphate ion and water species. In contrast, at potentials positive to $E_{\text {ref }}=0.24 \mathrm{~V}$, several features appear in the range $1300-1700 \mathrm{~cm}^{-1}$, which start to be developed at approximately $0.35 \mathrm{~V}$. The positive bands at 1405 and $1484 \mathrm{~cm}^{-1}$ coincide with those reported for TU at the copper $\mid$ aqueous borax [27] and platinum $\mid$ aqueous sulphuric acid [23] interface. The band at $1405 \mathrm{~cm}^{-1}$ has been assigned to symmetric $\mathrm{N}-$ $\mathrm{C}-\mathrm{N}$ and $\mathrm{C}-\mathrm{S}$ bond stretching, and $\mathrm{NH}_{2}$ rocking modes in TU [23,32,34], while the band at $1487 \mathrm{~cm}^{-1}$ corresponds to the asymmetric $\mathrm{C}-\mathrm{N}$ stretching and $\mathrm{NH}_{2}$ bending modes of TU [23,32,34]. Thus, TU molecules are consumed and the product formed is responsible for the negative band at $1435 \mathrm{~cm}^{-1}$. This frequency, however, can be assigned to active groups

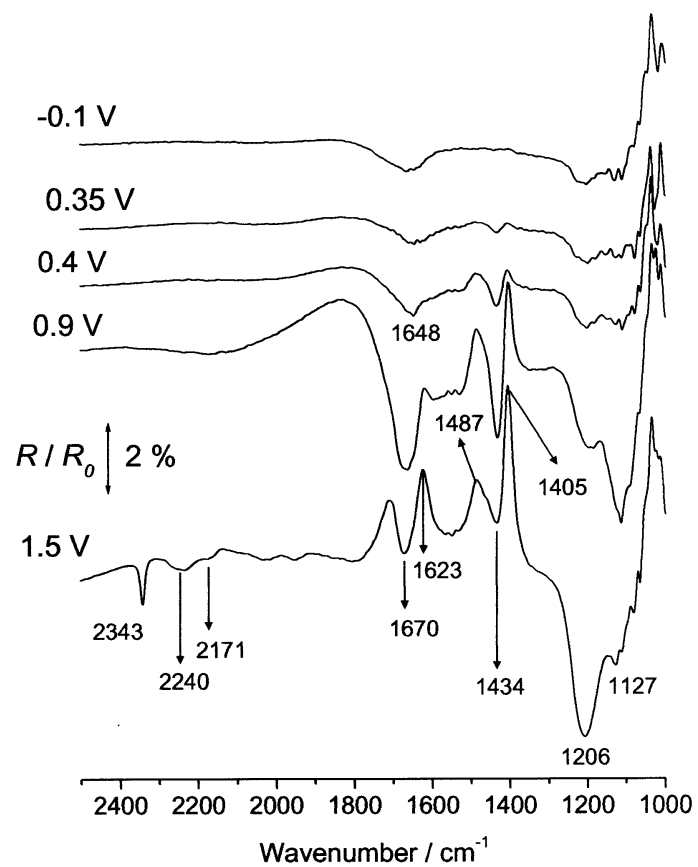

Fig. 6. p-Polarised light FTIRRAS spectra of gold in $0.1 \mathrm{M} \mathrm{TU}+0.5$ $\mathrm{M}$ sulphuric acid at different potentials. $E_{\mathrm{ref}}=0.24 \mathrm{~V}$. present in the TU molecule, and taking into account that at these potentials metal dissolution occurs [34], the product formed can be related to a gold-TU soluble complex according to

$\mathrm{Au}(\mathrm{s})+2 \mathrm{TU}(\mathrm{aq}) \rightarrow\left[\mathrm{Au}(\mathrm{TU})_{2}\right]^{+}(\mathrm{aq})+\mathrm{e}^{-}$

As gold in TU-containing solutions undergoes chemical or electrochemical dissolution $[7,24,35,36]$ forming $\left[\mathrm{Au}(\mathrm{TU})_{2}\right]^{+}$complex ions $[10,11]$, it seems reasonable to assign the $1405 / 1434 \mathrm{~cm}^{-1}$ bipolar band to the appearance/disappearance of TU from the solution due to the formation of the gold complex. Accordingly, the band at $1434 \mathrm{~cm}^{-1}$ is due to the soluble gold complex in aqueous sulphuric acid. This conclusion is supported by the band at $1434 \mathrm{~cm}^{-1}$ in the spectrum of solid $\left[\mathrm{Au}(\mathrm{TU})_{2}\right]_{2} \mathrm{SO}_{4}$ (Fig. 5). The blue-shift of these bands as compared to those of $\mathrm{TU}$ indicates an increase in the $\mathrm{C}-$ $\mathrm{N}$ and $\mathrm{C}-\mathrm{S}$ bond stretching vibration energy due to the greater double bond character of the $\mathrm{C}-\mathrm{N}$ bond, and a decrease in the $\mathrm{C}-\mathrm{S}$ bond order. This is consistent with the formation of a strongly polar sulphur-metal bond in the complex species. It should be noted that the blueshift of the $\mathrm{C}-\mathrm{N}$ and $\mathrm{C}-\mathrm{S}$ bands of TU has also been observed in solid copper-TU complexes [33], as well as during copper dissolution in TU-containing aqueous borax, where copper-TU complex is formed [27]. The positive band at $1623 \mathrm{~cm}^{-1}$ corresponds to the bending scissoring of the $\mathrm{NH}_{2}$ group of TU (Table 1).

The negative band at approximately $1648 \mathrm{~cm}^{-1}$ for $E=0.4 \mathrm{~V}$ (Fig. 6) correlates with the appearance of the positive bands at 1405 and $1484 \mathrm{~cm}^{-1}$. The wide feature near $1648 \mathrm{~cm}^{-1}$ shifting to $1673 \mathrm{~cm}^{-1}$ as $E$ is increased to $1.5 \mathrm{~V}$ can be assigned to the formation of FDS in solution (see Fig. 4b and Table 3). This band can be assigned to the bending of $\mathrm{NH}_{2}$ in the molecule of FDS $[23,32]$. According to this assignment, soluble FDS would be formed for $E>0.3 \mathrm{~V}$, i.e. during the development of peak Ia in the voltammogram (Fig. 1). However, water features can interfere in this frequency region, and therefore, for a definite identification of FDS absorption bands, FTIRRAS experiments performed in deuterium oxide solution are required, as described in Section 3.6.

The negative bands at 1127 and $1200 \mathrm{~cm}^{-1}$ (Fig. 6) are related to sulphate and bisulphate ion species [37], 
Table 3

Principal infrared bands of FDS

\begin{tabular}{|c|c|c|}
\hline Frequency $/ \mathrm{cm}^{-1}$ & Assignment & References \\
\hline 1055 & $\rho \mathrm{NH}_{2}+v_{\mathrm{as}} \mathrm{CN}_{2}$ & {$[32]$} \\
\hline 1095 & $\rho \mathrm{NH}_{2}+v_{\mathrm{s}} \mathrm{CN}_{2}$ & [32] \\
\hline 1400 & $v_{\mathrm{s}} \mathrm{NCN}+\rho \mathrm{NH}_{2}+v \mathrm{CS}$ & [32] \\
\hline 1585 & $\delta \mathrm{NH}_{2}+v_{\mathrm{as}} \mathrm{CN}_{2}$ & [32] \\
\hline 1630 & $\delta \mathrm{NH}_{2}+v_{\mathrm{as}} \mathrm{CN}_{2}$ & {$[32]$} \\
\hline 1654 & $\delta \mathrm{NH}_{2}$ & [32] \\
\hline 1650 & - & {$[23]$} \\
\hline
\end{tabular}

respectively. As $E$ is changed from 0.4 to $0.9 \mathrm{~V}$, the intensity of the band at $1127 \mathrm{~cm}^{-1}$ increases faster than that at $1200 \mathrm{~cm}^{-1}$, although the latter suddenly increases for $E=1.5 \mathrm{~V}$. The relative change in intensity of these bands can be caused by the formation of sulphate species from the complete electro-oxidation of $\mathrm{TU}$ at $1.5 \mathrm{~V}$, and the simultaneous local acidification of the solution accompanying the formation of the oxygencontaining layer on gold from water electro-oxidation. Although hydrogen ions from the anodisation process in part migrate outwards, another part is neutralised by sulphate ion migration inwards. The enrichment of anions at the interface is reflected in the increase in the sulphate band intensity [38]. To discriminate between bands coming from the TU electro-oxidation process and those associated with solution components, runs in aqueous perchloric acid were made (next section).

Finally, the spectrum recorded for $E=1.5 \mathrm{~V}$ (Fig. 6) shows other negative bands at 2343, 2171 and 2240 $\mathrm{cm}^{-1}$. The band at $2343 \mathrm{~cm}^{-1}$ corresponds to the $\mathrm{O}-$ $\mathrm{C}-\mathrm{O}$ asymmetric stretching [39] and reveals the formation of carbon dioxide from late TU electro-oxidation. The bands at 2171 and $2240 \mathrm{~cm}^{-1}$ would indicate the formation of $\mathrm{CN}$-compounds since the $\mathrm{C} \equiv \mathrm{N}$ stretching band for pure cyanamide is located at $2280 \mathrm{~cm}^{-1}$ [40] and for benzonitrile at $2235 \mathrm{~cm}^{-1}$ [41]. Cyanamide has been found as a product of TU electro-oxidation on platinum [22,23]. It should be noted, however, that the hydrolysis of nitriles in acid would yield the corresponding amide. The latter should exhibit a band at approximately $1660 \mathrm{~cm}^{-1}$ due to the $\mathrm{C}=\mathrm{O}$ stretching [41] that, in our case, would probably be obscured by the bands corresponding to water and FDS in this range of spectra.

Spectra run with s-polarised light, and a high angle of incidence, which provides only information on species in solution, are much less sensitive than spectra obtained with p-polarised light [38]. In our case, spectra obtained with s-polarised light show the same bands already observed with p-polarised light, although with a poorer definition.

\subsection{FTIRRAS of gold in $0.1 M$ aqueous $T U+$ perchloric} acid

To study the electrosorption and electro-oxidation of TU in the potential range of FDS formation and incipient gold electrodissolution, FTIRRAS spectra in perchloric acid solutions were run immersing the electrode either at $E_{\mathrm{i}}=E_{\mathrm{ref}}=-0.1 \mathrm{~V}$ and increasing $E$ stepwise from -0.1 up to $0.3 \mathrm{~V}$, or at $E_{\mathrm{i}}=E_{\text {ref }}=0.3 \mathrm{~V}$ and decreasing $E$ stepwise down to $-0.1 \mathrm{~V}$.

For $E_{\text {ref }}=-0.1 \mathrm{~V}$, i.e. at a potential below that corresponding to the electro-oxidation of TU to FDS, the stepwise increase in $E$ from -0.1 to $0.1 \mathrm{~V}$ produces no significant change in the spectra over the region $1000-1600 \mathrm{~cm}^{-1}$. However, for $E$ above $0.15 \mathrm{~V}$, positive bands at 1405 and $1487 \mathrm{~cm}^{-1}$, and negative bands at 1430, 1528 and $1642 \mathrm{~cm}^{-1}$ begin to be observed (Fig. 7). The intensity of these bands increases as $E$ is shifted positively.

On the other hand, starting from $E=0.3 \mathrm{~V}$ and decreasing $E$ stepwise to $-0.1 \mathrm{~V}$, the spectra show negative bands at 1405 and $1487 \mathrm{~cm}^{-1}$, and positive bands at 1430, 1528 and $1642 \mathrm{~cm}^{-1}$, the intensity of all these bands increasing as $E$ is decreased (Fig. 8). The spolarised light spectra (not shown) exhibited the same

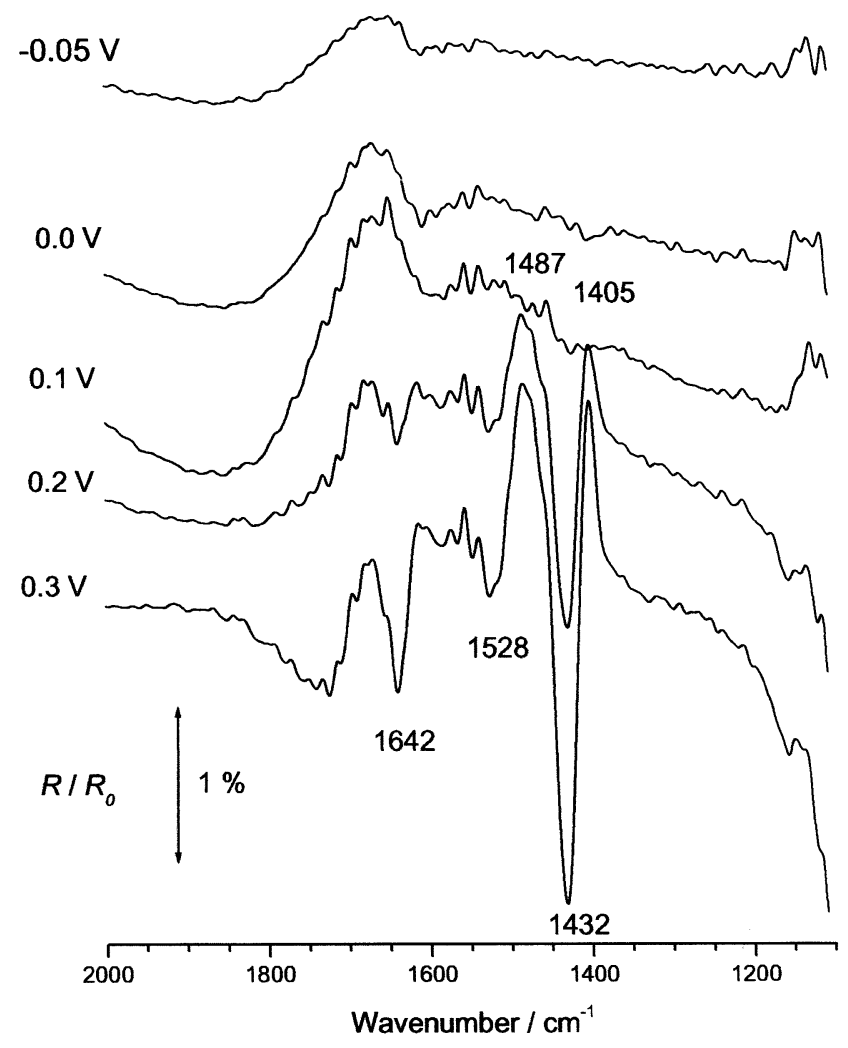

Fig. 7. p-Polarised light FTIRRAS spectra of gold in aqueous $0.1 \mathrm{M}$ $\mathrm{TU}+0.5 \mathrm{M}$ perchloric acid at different sampling potentials. The electrode was immersed at $E_{\mathrm{i}}=-0.1 \mathrm{~V}\left(E_{\mathrm{ref}}\right)$ and the potential increased stepwise. 


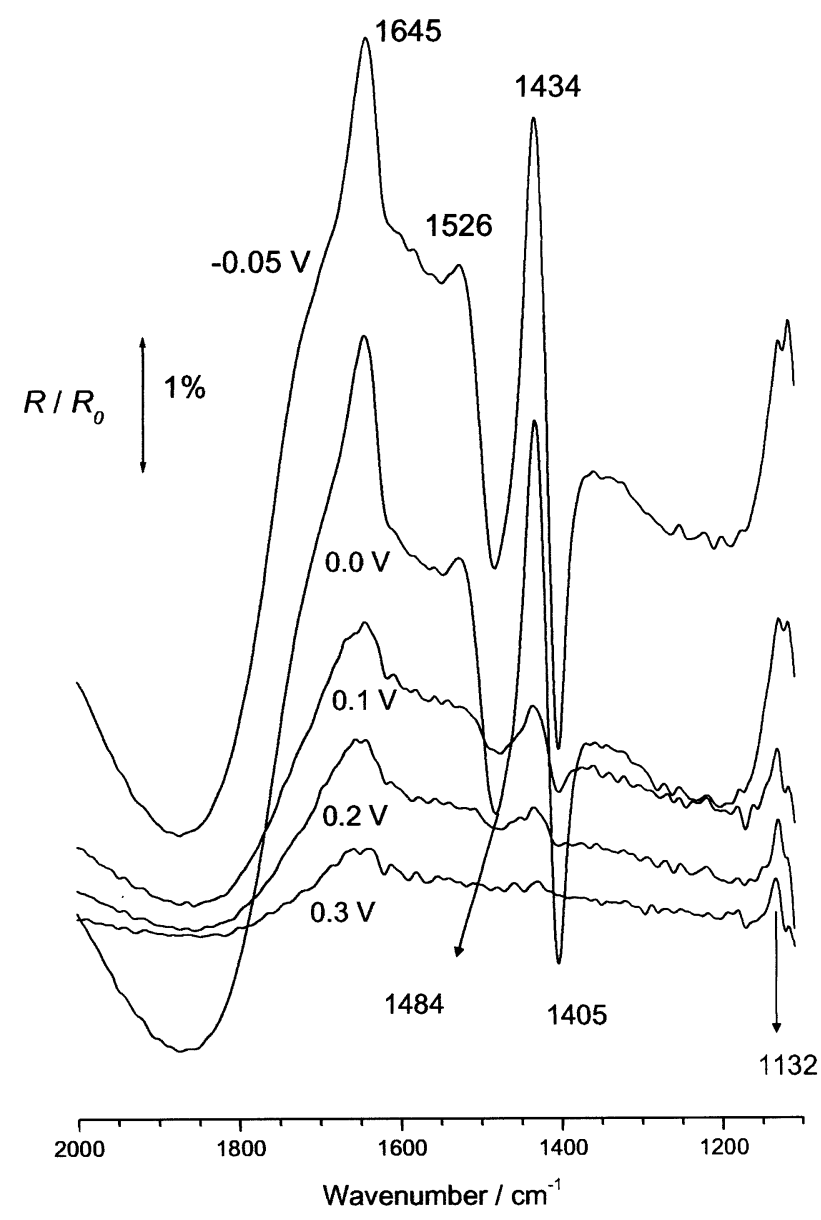

Fig. 8. p-Polarised light FTIRRAS spectra of gold in aqueous $0.1 \mathrm{M}$ $\mathrm{TU}+0.5 \mathrm{M}$ perchloric acid at different sampling potentials. The electrode was immersed at $E_{\mathrm{i}}=0.3 \mathrm{~V}\left(E_{\mathrm{ref}}\right)$ and the potential decreased stepwise.

bands confirming that all of them are related to species in solution.

The behaviour of the spectra when the electrode potential is either increased or decreased in the range $-0.1-0.3 \mathrm{~V}$ indicates that the same reactions proceeds when the potential direction is reversed.

The bands at 1480 and $1528 \mathrm{~cm}^{-1}$ show the formation of TU $\left(1480 \mathrm{~cm}^{-1}\right)$, and the disappearance of the soluble gold complex $\left(1528 \mathrm{~cm}^{-1}\right)$ (Fig. 8). This band shift agrees with data reported for copper-TU complexes [27,33]. The blue-shift of the band at $1480 \mathrm{~cm}^{-1}$ is accompanied by a decrease in intensity and the appearance of weaker bands at $1524-1514 \mathrm{~cm}^{-1}$ [27,33].

Finally, the negative band at approximately 1642 $\mathrm{cm}^{-1}$ (Fig. 8) appears for $E>0.15 \mathrm{~V}$, its intensity increasing as $E$ is changed from 0.3 to $-0.1 \mathrm{~V}$ and vice versa. Accordingly, this band should be related to soluble species that are produced at potentials more positive than $0.15 \mathrm{~V}$, in agreement with voltammetric results (Fig. 1). The band at $1642 \mathrm{~cm}^{-1}$ should be related to the bending of the $\mathrm{NH}_{2}$ group of FDS $[23,32]$, the first electro-oxidation product of TU on platinum $[19,30]$, copper [20], gold [16,36] and silver [28] electrodes. The presence of FDS bands was confirmed by running spectra in deuterium oxide as shown further on.

This set of experiments allowed us to conclude that for $E$ increasing from -0.1 to $0.3 \mathrm{~V}$, both the soluble gold complex and FDS species are formed. These products can be electroreduced to TU by decreasing $E$ backwards to $-0.1 \mathrm{~V}$. This behaviour agrees with the presence of the conjugated peaks Ia/Ic in the voltammograms within the same potential range (Fig. 1).

As $E$ is increased from 0.3 to $0.9 \mathrm{~V}$ (Fig. 9), the intensity of the negative bands at $1120 \mathrm{~cm}^{-1}$ due to perchlorate ions increases because of the local accumulation of these ions at the positively charged gold surface. Simultaneously, the intensity of both the positive bands at 1405 and $1483 \mathrm{~cm}^{-1}$ related to the depletion of TU, and the negative bands at 1434 and $1530 \mathrm{~cm}^{-1}$, related to soluble gold complex increases as $E$ is shifted positively, can be observed.

On the other hand, the complex band in the region $1600-1700 \mathrm{~cm}^{-1}$ consists of two negative bands centred at 1640 and $1690 \mathrm{~cm}^{-1}$ and a minimum at $1660 \mathrm{~cm}^{-1}$, probably associated with a positive band. The intensity of these negative bands also increases with $E$, in contrast to the intensity of the minimum at $1660 \mathrm{~cm}^{-1}$ that tends to disappear (Fig. 9).

For $E>1.2 \mathrm{~V}$, i.e., at potentials related to the formation of the oxygen-containing layer on gold, the spectra in the $1000-2500 \mathrm{~cm}^{-1}$ region (Fig. 9) exhibit negative bands at 1120 and $1200 \mathrm{~cm}^{-1}$ corresponding to sulphate and bisulphate, their intensity increasing as $E$ is shifted positively. For $E=1.5 \mathrm{~V}$ the band at $1200 \mathrm{~cm}^{-1}$ increases at the expense of the band at $1120 \mathrm{~cm}^{-1}$. These results indicate that the formation of sulphate ions from TU electro-oxidation occurs in the potential range where the formation of the oxygen-containing layer on gold takes place. Presumably, the local acidification caused by the anodisation modifies the sulphate/bisulphate concentration ratio at the thin layer of solution. This would explain the evolution of spectra with $E$ at such potentials.

It should be noted that the negative band at 1127 $\mathrm{cm}^{-1}$, exhibiting something like a hump at $1100 \mathrm{~cm}^{-1}$, is actually a complex band involving the absorption of both sulphate and perchlorate ions. The major contribution to this complex band comes from perchlorate ions that migrate from the bulk to the thin layer of solution in contact with the electrode, increasing the local concentration of these ions progressively with $E$. The increasing migration of perchlorate ions from the bulk towards the electrode surface is required to balance the positive charge flow due to the formation of positive ions such as the gold-TU complex and protons, the latter being produced during the formation of the oxygen-containing layer on gold. Besides, the step 


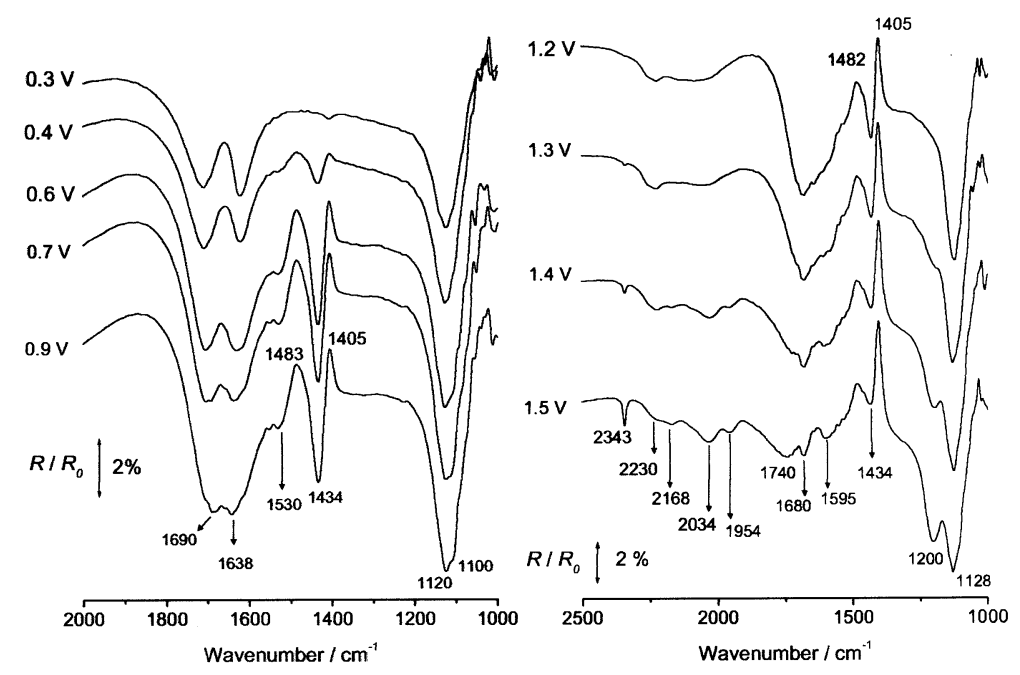

Fig. 9. p-Polarised light FTIRRAS spectra of gold in aqueous $0.1 \mathrm{M} \mathrm{TU}+0.1 \mathrm{M}$ perchloric acid at different sampling potentials. $E_{\text {ref }}=0.24 \mathrm{~V}$.

between sampling potentials also causes a charge to pass from the working to the auxiliary electrode, which is transported by ions migrating between the thin layer cavity and the bulk of the electrolyte $[41,42]$. On the other hand, the depletion of TU can be followed through the potential-dependent intensity of the positive bands at 1405 and $1485 \mathrm{~cm}^{-1}$, although this is not feasible with the negative band at $1435 \mathrm{~cm}^{-1}$ that is rather insensitive to changes in $E$. The different $E$ dependences of these bands suggests that the electrodissolution of gold as a complex species is dumped by an increasing passivation of the gold surface. Passivation occurs at potentials where sulphate, carbon dioxide and $\mathrm{CN}$-containing species are formed.

As $E$ is increased to $1.5 \mathrm{~V}$, a broad asymmetric feature is observed in the region 1500 and $1800 \mathrm{~cm}^{-1}$, which develops into two bands centred at $1680 \mathrm{~cm}^{-1}$. Also the development of a new band at $1740 \mathrm{~cm}^{-1}$ can be observed (Fig. 9b).

For $E \geqslant 1.3 \mathrm{~V}$, the band at $2343 \mathrm{~cm}^{-1}$ confirms the formation of carbon dioxide and the small negative bands observed in the range $1800-2500 \mathrm{~cm}^{-1}$ can be assigned to the formation of $\mathrm{C} \equiv \mathrm{N}$-containing species, probably cyanamide [23].

When $E$ exceeds the threshold potential for water electro-oxidation on gold an oxygen-containing layer according to

$$
\begin{aligned}
& \mathrm{Au}+\mathrm{H}_{2} \mathrm{O} \rightarrow \mathrm{Au}(\mathrm{OH})_{\mathrm{ad}}+\mathrm{H}^{+}+\mathrm{e}^{-} \\
& \mathrm{Au}(\mathrm{OH})_{\mathrm{ad}} \rightarrow \mathrm{Au}(\mathrm{O})_{\mathrm{ad}}+\mathrm{H}^{+}+\mathrm{e}^{-}
\end{aligned}
$$

is formed first, followed by gold oxide formation when $E>1.2 \mathrm{~V}[43-45]$.

Then, $\mathrm{OH} / \mathrm{O}$ species contribute to the formation of both carbon dioxide and sulphate/bisulphate species from TU and TU byproducts. Adsorbed TU byproducts such as FDS and S have been observed by STM imaging on $\mathrm{Au}\left(\begin{array}{lll}1 & 1 & 1\end{array}\right)$ [25] at potentials above $0.3 \mathrm{~V}$, and detected by XPS and FTIRRAS for Ag (llll 11 [ [28].

Thus, the results obtained either in sulphuric or perchloric acid solutions indicate that TU electrooxidation at potentials up to $1.5 \mathrm{~V}$ results in the formation of both $\mathrm{O}$ - and $\mathrm{CN}$-containing products.

Spectra recorded with s-polarised light exhibit the same bands observed with p-polarised light spectra, indicating that all the observed bands are related to the formation or depletion of species in solution.

\subsection{FTIRRAS spectra of gold in $0.1 \mathrm{MTU}+0.1 \mathrm{M}$ sulphuric acid in $\mathrm{D}_{2} \mathrm{O}$}

To diminish the interference of water and to avoid as much as possible that from the acid, $\mathrm{p}$ and $\mathrm{s}$ spectra using $0.1 \mathrm{M} \mathrm{TU}+0.1 \mathrm{M}$ sulphuric acid in deuterium oxide, in the range $0.3-1.5 \mathrm{~V}$ and $E_{\text {ref }}=0.2 \mathrm{~V}$ were obtained. In deuterated acid solutions both TU and FDS amine hydrogens are readily exchanged with deuterium from the solvent [46]. As a result, absorption bands for deuterated TU appear at 1388 and $1519 \mathrm{~cm}^{-1}$ [23,47], and for deuterated FDS at 1399 and $1631 \mathrm{~cm}^{-1}$ [23] (Table 4).

The p-polarised light spectra run from 0.3 to $0.9 \mathrm{~V}$ (Fig. 10) show positive bands at 1343, 1382 and 1516 $\mathrm{cm}^{-1}$, and negative bands at 1236, 1395, 1560 and 1632 $\mathrm{cm}^{-1}$. Bipolar bands are defined by the pair of peaks at $1382 / 1395 \mathrm{~cm}^{-1}$ and $1516 / 1560 \mathrm{~cm}^{-1}$. The positive bands at 1382 and $1516 \mathrm{~cm}^{-1}$ are assigned to the depletion of deuterated TU, and the band at $1395 \mathrm{~cm}^{-1}$ to the appearance of deuterated FDS [23] that can already be seen for $E=0.4 \mathrm{~V}$. The negative band at 1632 $\mathrm{cm}^{-1}$, which has also been assigned to deuterated FDS [23], appears for $E \geqslant 0.6 \mathrm{~V}$. Moreover, for $E=1.5 \mathrm{~V}$, the intensity of the band at $1398 \mathrm{~cm}^{-1}$ tends to decrease, while that of the band at $1632 \mathrm{~cm}^{-1}$ increases con- 
Table 4

Principal infrared bands of deuterated TU and FDS

\begin{tabular}{lll}
\hline Frequency/cm & Assignment & References \\
\hline $1390(\mathrm{TU})$ & $v_{\mathrm{s}} \mathrm{CN}_{2}$ & {$[29]$} \\
$1474(\mathrm{TU})$ & $v_{\mathrm{as}} \mathrm{CN}_{2}$ & {$[29]$} \\
$1190(\mathrm{TU})$ & $\delta \mathrm{ND}_{2}$ & {$[29]$} \\
$1140(\mathrm{TU})$ & $\delta \mathrm{ND}_{2}$ & {$[29]$} \\
$1131(\mathrm{TU})$ & $\delta \mathrm{ND}_{2}$ & {$[58]$} \\
$1284(\mathrm{TU})$ & $\delta \mathrm{ND}_{2}$ & {$[58]$} \\
$1355(\mathrm{TU})$ & $v_{\mathrm{s}} \mathrm{C}-\mathrm{N}$ & {$[58]$} \\
$1449(\mathrm{TU})$ & $v_{\mathrm{as}} \mathrm{C}-\mathrm{N}$ & {$[58]$} \\
$1388(\mathrm{TU})$ & $\delta \mathrm{ND}_{2}$ & {$[47]$} \\
$1507(\mathrm{TU})$ & $\delta \mathrm{ND}_{2}$ & {$[47]$} \\
$1399(\mathrm{FDS})$ & & {$[23]$} \\
$1631(\mathrm{FDS})$ & & {$[23]$} \\
\hline
\end{tabular}

tinuously (Fig. 10). The apparent lower intensity of the positive band at $1398 \mathrm{~cm}^{-1}$ is probably due to the enhancement of the TU band at $1382 \mathrm{~cm}^{-1}$ that shifts the FDS band upwards.

The new negative band at $1560 \mathrm{~cm}^{-1}$ and the positive band at $1516 \mathrm{~cm}^{-1}$ constitute a bipolar band presumably associated with the appearance of the gold complex and the disappearance of TU. Therefore, there is a red shift of the bands related to the bending of the $\mathrm{NH}_{2}$ groups caused by deuteration. As $E$ is increased beyond $1.2 \mathrm{~V}$, the negative band at $1562 \mathrm{~cm}^{-1}$ disappears and a new small negative band at $1587 \mathrm{~cm}^{-1}$ can be seen.

On the other hand, the negative band at $1236 \mathrm{~cm}^{-1}$ is the only potential-dependent band, as it shifts from approximately 1236 to $1252 \mathrm{~cm}^{-1}$ when $E$ increases from 0.8 to $1.5 \mathrm{~V}$. Bisulphate ions formed in solution are responsible for the high intensity of this band. However, overlapping with a surface feature causes the band centre to shift with $E$. The latter is likely to be associated with an adsorbed species with a shift of $27 \mathrm{~cm}^{-1} \mathrm{~V}^{-1}$. This shift is comparable to that observed for sulphate on polycrystalline platinum $\left(20-30 \mathrm{~cm}^{-1} \mathrm{~V}^{-1}\right)$ [37] and lower than the $85 \mathrm{~cm}^{-1} \mathrm{~V}^{-1}$ observed for gold $\left(\begin{array}{lll}1 & 1 & 1\end{array}\right)$ [48] or the 40-58 $\mathrm{cm}^{-1} \mathrm{~V}^{-1}$ for platinum $\left(\begin{array}{lll}1 & 0 & 0\end{array}\right)$ [49]. For gold (1 111$)$, FTIRRAS spectra of adsorbed sulphate exhibit a prominent SO stretching band between 1155 and $1220 \mathrm{~cm}^{-1}$, depending on the applied potential [48]. The frequency shift of adsorbed sulphate from that corresponding to the solution phase species is a feature usually expected from the change of symmetry produced upon adsorption [50].

The major adsorption of bisulphate ions on gold can be discarded because at high positive potentials, the bisulphate ion is polarised concentrating the electron density towards the electrode surface. Then, the oxygen atoms that are away from the electrode surface become less negatively charged increasing the acid character of bisulphate. Consequently, any adsorbed bisulphate ion tends to dissociate on the surface into adsorbed sulphate and hydrogen ions that migrate outwards [49]. This is consistent with previous FTIR data for gold (lllll) in sulphate/bisulphate solutions that showed the absence of bisulphate species on the metal surface [48].

It should be noted that the appearance of adsorbed sulphate is observed in the potential range related to the electro-oxidation of TU to sulphate assisted by the initial stage of water discharge on gold yielding $\mathrm{OH}$ and $\mathrm{O}$ adsorbed species (Eq. (2)). Sulphate adsorption on gold produces ordered structures [48,51] and brings about changes in surface relaxation and surface stress of the gold surface [52].

s-Polarised light spectra exhibit all but the negative band at $1236 \mathrm{~cm}^{-1}$ observed for p-polarised light
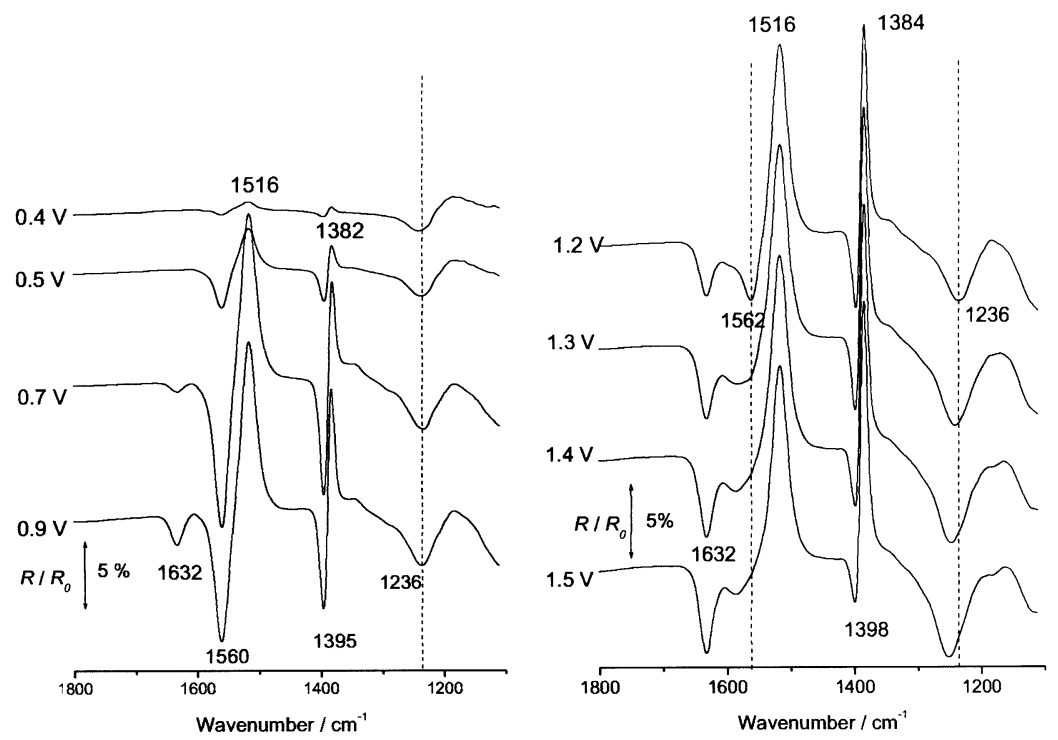

Fig. 10. p-Polarised light FTIRRAS spectra of gold in deuterium oxide $0.1 \mathrm{M} \mathrm{TU}+0.1 \mathrm{M}$ sulphuric acid at different sampling potentials. $E_{\text {ref }}=0.2$ V. 
spectra. This indicates that, except the adsorbed sulphate, all the rest of the species detected are in solution.

\section{Conclusions}

(1) The voltammetric electro-oxidation of TU on gold for $c_{\mathrm{TU}}=0.1 \mathrm{M}$ involves two main consecutive stages characterised by anodic peaks at approximately 0.5 and $1.0 \mathrm{~V}$, related to the formation of FDS and the electrodissolution of gold as gold-TU complex ions.

(2) FTIRRAS spectra allow monitoring the electrooxidation reaction of both gold and TU through the appearance of loss and gain bands related to the gold complex and TU byproduct species.

(3) According to FTIRRAS spectra, gold electrodissolution starts at approximately $E=0.15 \mathrm{~V}$ and increases as $E$ is increased. The soluble gold-TU complex is electroreduced when $E$ is decreased from $0.15 \mathrm{~V}$.

(4) The electro-oxidation of TU and the electrodissolution of gold are concomitant processes that at potentials below $0.9 \mathrm{~V}$ produce $\mathrm{FDS}$ and $\left[\mathrm{Au}(\mathrm{TU})_{2}\right]^{+}$ soluble species. The formation and electroreduction of these species are complementary processes.

(5) In the potential range related to the first water discharge step on gold, the main electro-oxidation products are carbon dioxide, sulphate and $\mathrm{CN}$-containing species. The formation of O-containing products from $\mathrm{TU}$ and $\mathrm{TU}$ byproducts is assisted by $\mathrm{OH}$ and $\mathrm{O}$ adsorbates on the gold surface and gold oxide produced from water discharge.

(6) For $E>1.2 \mathrm{~V}$, both adsorbed and soluble sulphate species are formed. Adsorbed sulphate exhibits a band shift of $27 \mathrm{~cm}^{-1} \mathrm{~V}^{-1}$. Local acidification at the anodic interface presumably modifies the sulphate/bisulphate concentration ratio.

\section{Acknowledgements}

This work was supported financially by the Consejo Nacional de Investigaciones Científicas y Técnicas (CONICET), Agencia Nacional de Promoción Científica y Tecnológica (PICT 98 06-03251) of Argentina and the Comisión de Investigaciones Científicas de la Provincia de Buenos Aires (CIC).

\section{References}

[1] K.C. Pillai, R. Narayan, J. Electrochem. Soc. 125 (1978) 1393

[2] A.S.M.A. Haseeb, P.L. Schilardi, R.C.V. Piatti, A.E. Bolzán, R.C. Salvarezza, A.J. Arvia, J. Electroanal. Chem. 500 (2001) 543.

[3] L.M. Gassa, J. Lambi, A.E. Bolzán, A.J. Arvia, J. Electroanal. Chem. 32 (2002) 71.

[4] K. Sykut, J. Saba, B. Marczewska, G. Daimata, J. Electroanal. Chem. 178 (1984) 295.
[5] R.M. Souto, S. Gonzáles, A. Arévalo, J. Electroanal. Chem. 216 (1987) 273.

[6] A. Szymaszek, J. Biernat, L. Pajdowski, Electrochim. Acta 22 (1977) 359.

[7] I.N. Plaksin, M.A. Kozhukhova, C.R. Acad. Sci. USSR 31 (1941) 671.

[8] T. Groenewald, Hydrometallurgy 1 (1976) 277.

[9] G. Deschènes, E. Ghali, Hydrometallurgy 20 (1988) 179.

[10] L.C. Porter, J.P. Fackler, J. Costamagna, R. Schmidt, Acta Cryst. C48 (1992) 1751.

[11] O.E. Piro, E.E. Castellano, R.C.V. Piatti, A.E. Bolzán, A.J. Arvia, Acta Cryst. C58 (2002) 252

[12] B.H. Loo, Phys. Lett. 89 (1982) 346.

[13] M. Fleischmann, I.R. Hill, G. Sundholm, J. Electroanal. Chem. 157 (1983) 359.

[14] R. Holze, S. Shomaker, Electrochim. Acta 35 (1990) 613.

[15] A.E. Bolzán, R.C.V. Piatti, R.C. Salvarezza, A.J. Arvia, J. Appl. Electrochem. 32 (2002) 611.

[16] A.E. Bolzán, R.C.V. Piatti, A.J. Arvia, J. Electroanal. Chem., in press.

[17] P. Gao, M.L. Patterson, M.A. Tadayyoni, M.J. Weaver, Langmuir 1 (1985) 173.

[18] H. Wroblowa, M. Green, Electrochim. Acta 8 (1963) 679.

[19] A.E. Bolzán, I.B. Wakenge, R.C. Salvarezza, A.J. Arvia, J. Electroanal. Chem. 475 (1999) 181

[20] A.E. Bolzán, I.B. Wakenge, R.C.V. Piatti, R.C. Salvarezza, A.J. Arvia, J. Electroanal. Chem. 501 (2001) 241.

[21] P.W. Preisler, L. Berger, J. Am. Chem. Soc. 69 (1947) 322.

[22] P.C. Gupta, Z. Anal. Chem. 196 (1963) 412

[23] M. Yan, K. Liu, Z. Jiang, J. Electroanal. Chem. 408 (1996) 225.

[24] T. Groenewald, J. Appl. Electrochem. 5 (1975) 71.

[25] O. Azzaroni, B. Blum, R.C. Salvarezza, A.J. Arvia, J. Phys. Chem. B 104 (2000) 1395

[26] J.O.M. Bockris, M.A. Habib, J.L. Carbajal, J. Electrochem. Soc. 131 (1984) 3032.

[27] S.N. Port, S. Ceré, D.J. Schiffrin, J. Electroanal. Chem. 432 (1997) 215.

[28] V. Brunetti, B. Blum, R.C. Salvarezza, A.J. Arvia, P.L. Schilardi, A. Cuesta, J. Gayone, G. Zampieri, J. Phys. Chem. B 106 (2002) 9831.

[29] D. Papapanayiotou, R.N. Nuzzo, R.C. Alkire, J. Electrochem. Soc. 145 (1998) 3366.

[30] S.J.J. Reddy, V.N. Krishnan, J. Electroanal. Chem. 27 (1970) 473.

[31] V. Gaspar, A.S. Mejerovich, M.A. Meretukov, J. Schmiedl, Hydrometallurgy 34 (1994) 369.

[32] G. Peyronel, W. Malavasi, A. Pignedoli, Spectrochim. Acta 39A (1983) 617

[33] R.C. Bott, G.A. Bowmaker, C.A. Davis, G.A. Hope, B.E. Jones, Inorg. Chem. 37 (1998) 651.

[34] S.N. Port, S.L. Horswell, R. Raval, D.J. Schiffrin, Langmuir 12 (1996) 5934.

[35] R.G. Schulze, J. Metals (1984) 62.

[36] H. Zhang, I.M. Ritchie, S.R.L. Brooy, J. Electrochem. Soc. 148 (2001) D146.

[37] K. Kunimatsu, M. Samant, H. Seki, M.R. Philpott, J. Electroanal. Chem. 243 (1988) 203

[38] T. Iwasita, F. Nart, in: H. Gerischer, C.W. Tobias (Eds.), Advances in Electrochemical Science and Engineering, vol. 4, VCH, Weinheim, 1995, p. 123.

[39] G. Herzberg, Molecular Spectra and Molecular Structure II: Infrared and Raman Spectra of Polyatomic Molecules, Van Nostrand Reinhold, New York, 1945.

[40] C.J. Pouchert, The Aldrich Library of Infared Spectra, third ed., Aldrich Chemical Co, Milwakee, 1981.

[41] A. Chen, J. Richer, S.G. Roscoe, J. Lipkowski, Langmuir 13 (1997) 4737. 
[42] N.S. Marinkovič, J.J. Calvente, Z. Kovčov, W.R. Fawcett, J. Electrochem. Soc. 143 (1996) L171.

[43] H. Angerstein-Kozlowska, B.E. Conway, B. Barnett, J. Mozota, J. Electroanal. Chem. 100 (1979) 417.

[44] H. Angerstein-Kozlowska, B.E. Conway, A. Hamelin, L. Stoicoviciu, Electrochim. Acta 31 (1986) 1051.

[45] C.M. Ferro, A.J. Calandra, A.J. Arvia, J. Electroanal. Chem. 65 (1975) 963.

[46] D. Hadžic, J. Kidrič, Z.K. Kneževic, B. Barlič, Spectrochim. Acta A 32 (1976) 693.

[47] G.B. Aitken, J.L. Duncan, G.P. McQuillan, J. Chem. Soc. A (1971) 2695

[48] G.J. Edens, X.P. Gao, M. Weaver, J. Electroanal. Chem. 375 (1994) 357.
[49] F.C. Nart, T. Iwasita, M. Weber, Electrochim. Acta 39 (1994) 2093.

[50] F.C. Nart, T. Iwasita, J. Electroanal. Chem. 322 (1992) 289.

[51] O.M. Magnussen, J. Hegebock, J. Hotlos, R.J. Behm, Faraday Discuss. (1992) 329.

[52] R.J. Nichols, T. Nouar, C.A. Lucas, W. Haiss, W.A. Hofer, Surf. Sci. 513 (2002) 263.

[53] A. Yamaguchi, P.B. Penland, S. Mizushima, T.J. Lane, C. Curran, J.V. Qualgiano, J. Am. Chem. Soc. 80 (1958) 527.

[54] J. Stewart, J. Chem. Phys. 26 (1957) 248.

[55] R. Rivest, Can. J. Chem. 40 (1962) 2234.

[56] M.M. El-Etri, W.M. Scovell, Inorg. Chem. 29 (1990) 480.

[57] S.N. Cesaro, Vibrational Spectroscopy 16 (1998) 55.

[58] L. Bencivenni, S.N. Cesaro, A. Pieretti, Vibrational Spectroscopy 18 (1998) 91. 